\title{
Usage of Antimony Trioxide, Aluminum Hydroxide and Zinc Borate in Grp Composite Production as Fire-Retardant Additives: An Experimental Research
}

\author{
Ahmet Beycioğlu ${ }^{1}$ iD, Eda Yılmaz ${ }^{2}$ iD, Suna Çetin ${ }^{3}$ iD, Neslihan Gökçe ${ }^{4}$ iD, Hüseyin Yılmaz Aruntaş 5 iD \\ ${ }^{1}$ Deparment of Civil Engineering, Faculty of Engineering, University of AAT Science and Technology, Adana, O1360, TURKEY \\ ${ }^{2}$ Turkish Standardization Institute, 06100, Ankara, TURKEY \\ ${ }^{3}$ Deparment of Ceramic, Faculty of Fine Art, University of Cukurova, Adana, 01330, TURKEY \\ ${ }^{4}$ Superlite Pipe, 81900, Düzce, TURKEY \\ ${ }^{5}$ Deparment of Civil Engineering, Faculty of Technology, University of Gazi, Ankara, 06560, TURKEY
}

Başvuru/Received: 04/11/2020

Kabul / Accepted: 14/12/2020

Çevrimiçi Basım / Published Online: 18/01/2021

Son Versiyon/Final Version: 18/01/2021

\section{$\ddot{O} \mathbf{z}$}

In this study, it was aimed to investigate the usability of compounds in inorganic structure and the effect of these compounds used in composites on the mechanical properties of composites in order to give fire retardant properties to glass fiber reinforced polyester composites (CTP). Antimony trioxide $\left(\mathrm{Sb}_{2} \mathrm{O}_{3}\right)$, aluminum hydroxide $\left(\mathrm{Al}(\mathrm{OH})_{3}\right)$ and zinc borate $\left(2 \mathrm{ZnO}_{3} \cdot \mathrm{BrO}_{3} \cdot 3 \mathrm{H}_{2} \mathrm{O}\right)$ were added by different proportions $(5 \%, 10 \%, 15 \%, 20 \%, 25 \%, 30 \%)$ to resin blends to improve the non-flammability of the composites. In experimental study, the combustion behavior of the doped CTP composites produced using different inorganic compounds was determined by international combustion standards ASTM D-635, ASTM D-3801 and ASTM D-5048. In addition, thermo gravimetric analysis (TGA) was applied in order to determine the thermal behavior of the produced GRP composites due to temperature increase and tensile test were applied according to ASTM 638-14.As a result, when the flame retardant additive ratio is $15 \%$ or more in the GRP composites, the hand lay production became difficult due to the increase in viscosity. According to ASTM D-3801, when 30\% AH (Aluminum hydroxide) is used, non-combustible material in V1 class can be produced. All FRP composites containing flame retardants were included in the HB (Horziontal burning) slowly burning material class. Flame retardant use generally reduced the tensile strength of GRP composites, but it was found that $10 \%$ increase in AT (Antimony trioxide)-doped CTPs.

\section{Key Words}

"Glass fiber, Fire retardant composites, Non-flammability, Tensile test" 


\section{Introduction}

Lately, studies on polymer composites reinforced with fibers have accelerated with the developing technology. Polymer composites are easy to process, lightness, corrosion resistance, etc. finds application in different sectors as superior materials due to their properties (Şahin, 2015). The main production purpose of composite materials is to combine the properties of different materials that are considered to obtain good and superior properties (Bulut et al., 2011).

At least one of these two or more materials should be the material called matrix as the main binder of the composite, and the other should be the material that gives the composite superior feature and is called reinforcement (Valery et al., 2001). Metal, ceramic and polymer materials are used as matrix materials in produced composites today (Kaya, 2016).

Nowadays, glass fiber reinforced composites (GRP) are among the most widely used polymer-based composites. GRPs are highly preferred materials in various sectors with their low density, ease of forming and high strength (Bulut et al., 2011). However, it is known that they have flammability properties because they are polymer-based (Saçak, 2005). When exposed to fire, polymeric materials are composed of hydro-carbon chains that rapidly burn by releasing high amounts of heat, flame and smoke (Dittenber et al., 2006; Bar et al., 2015; Cullis et al., 1981; Camino et al., 1991).

Various studies are carried out in the literature to increase the burning resistance of the polymer. The flame retardants (FR) used in these studies can affect the burning physically, chemically or both together (Saçak, 2005). In terms of human safety, it is dangerous to use polymeric composite materials without any FR process. The use of FR-composite materials for different applications that increase safety awareness in consumers has become a concern of developed and developing countries, including the European Community and the United States government (Bar et al., 2015; Sorathia at al., 1992).

Thermoset type composites also burn rapidly in fire. Manfredi et al., 2006 prepared a series of composites. These composites are modacrylic, unsaturated polyester and jute as reinforcement material, linen, sisal and glass respectively. The flame retardant behavior of these composite materials was compared. It was noticed that flax fibre reinforced composite allows to leave the highest amount of heat while glass fibre reinforced composite shows the lowest release (Bar et al., 2015).

Magnesium hydroxide is one of the most important flame retardants that is widely used in the polymer industry (Hornsby et al., 1994; Carpentier et al., 2000). Sangcheol et al., 2003 has studied smoke suppression and flame retardancy of magnesium hydroxide filled polyethylene composites. The experimental results demonstrated that the flame retardancy shown by magnesium hydroxide could be increased effectively by adding talc and zinc borate.

The flame retardant properties of polymer composites are enhanced by the addition of higher amounts of flame retardants than the group of metallic hydroxides such as aluminum hydroxide and magnesium hydroxide. However, especially the flexural strength and tensile strength of the produced polymeric composites are weakened. The highly effective flame retardant magnesium hydroxide is another type of magnesium hydroxide that dominate better flame retardant property than that of the common magnesium hydroxide (Maira et al., 2015; Tasdemir et al., 2011).

In this study, it was aimed to investigate the usability of compounds in inorganic structure and the effect of these compounds used in composites on the mechanical properties of composites in order to give fire retardant properties to glass fiber reinforced polyester composites (GRP).

\section{Materials and Method}

\subsection{Materials}

In the production of composites, orthophthalic unsaturated polyester resin with thermoset characteristic as binder, Methyl Ethyl Ketone Peroxide as initiator, Cobalt Octoate as accelerator were used. In addition, 30x30 cm matt felt glass fibers were used as reinforcing material to produce all composites containing flame retardant powders. All materials used in this research are given in Figure 1.

The resin used in the production of composites has medium reactivity and medium viscosity. It is suitable for GRP production by hand lay-up method. The properties of resin and matt felt glass fibers as main materials of composites were given in Table 1 and Table 2 . 


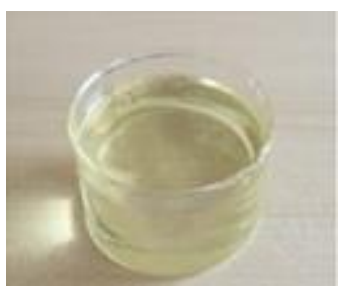

Resin

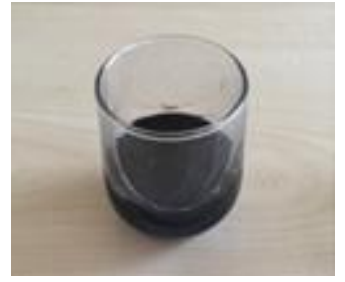

Cobalt octoate

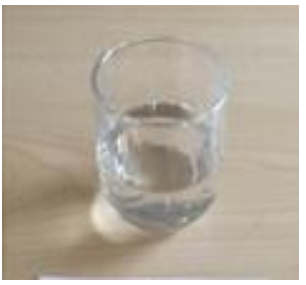

MEK-P

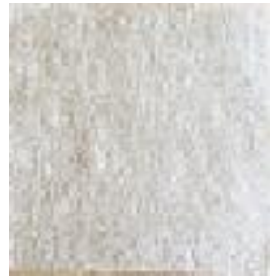

Matt felt glass fiber

Figure 1. Materials used in study

Table 1. Properties of Unsaturated Polyester Resin

\begin{tabular}{lr}
\hline Features & Range \\
Viscosity $23{ }^{\circ} \mathrm{C}(\mathrm{cps})$ & Winter season- 350-450 \\
Appearance & Summer season-500-550 \\
Monomer Ratio (\%) & Transparent \\
Acid value (mgKOH/g) & $38-42$ \\
Gel time (min.) & $18-22$ \\
& Winter season $-08-12$ \\
\hline
\end{tabular}

Table 2. Properties of matt felt glass fiber

\begin{tabular}{lr}
\hline Features & Value \\
Glass Type & $\mathrm{E}$ \\
Binder Type & Silane \\
Trimmed Bundle & $50 \mathrm{~mm}$ \\
Resin Harmony & Polyester \\
Weight unit area & $225 \mathrm{~g} / \mathrm{m}^{2}$ \\
Soakage & Rapid \\
\hline
\end{tabular}

In addition to main materials of composites, antimony trioxide (AT), aluminum hydroxide (AH) and zinc borate (ZB) powders were used as flame retardant additives (FR) in order to reduce the flammability risk of the composites. Images and chemical formulas of powders used in this research were given in Table 3 and Figure 2.

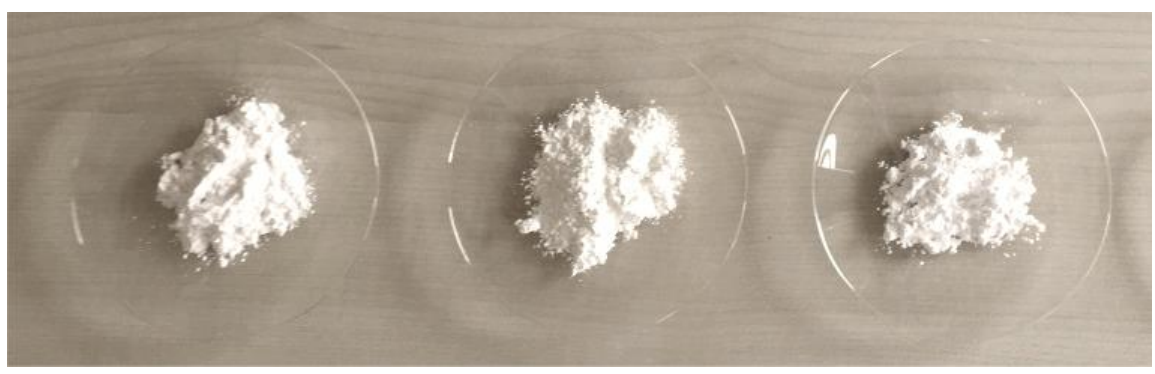
Aluminum hydroxide
Antimony trioxide
Zinc borate

Figure 2. Images of flammability additives

Table 3. Flammability additives and their properties

\begin{tabular}{lll}
\hline Compound & Formula & Appearance \\
AH & $\mathrm{Al}(\mathrm{OH})_{3}$ & White powder \\
AT & $\mathrm{Sb}_{2} \mathrm{O}_{3}$ & White powder \\
$\mathrm{ZB}$ & $2 \mathrm{ZnO} .3 \mathrm{BrO}_{3} .3 \mathrm{H}_{2} \mathrm{O}$ & White powder \\
\hline
\end{tabular}




\subsection{Method}

In the experimental stage, burning characteristics and axial tensile performance were performed according to ASTM D-635-18, ASTM D5048 and ASTM 638-14, respectively. Test samples of all composites containing AH, AT and ZB (including different percentages of each additive) were prepared with different dimensions to apply burning and axial tensile tests in accordance with related ASTM standards. The size and number of test samples prepared for each composites containing AH, AT and ZB were given in Table 4 .

Table 4. The size and number of test samples prepared for each composites

\begin{tabular}{|c|c|c|c|c|c|}
\hline & \multicolumn{4}{|c|}{ Combustion Test } & Axial tensile test \\
\hline \multirow{8}{*}{$\begin{array}{l}\text { Sample } \\
\text { Code }\end{array}$} & Percentage & ASTM & ASTM & ASTM & ASTM \\
\hline & of compound & D635-18 & D5048 & D3801-10 & D638-14 \\
\hline & $(\%)$ & $\begin{array}{l}125 \times 13 \times 3 \mathrm{~m} \\
\mathrm{~m} \text { diameter }\end{array}$ & $\begin{array}{l}150 \times 150 \mathrm{~mm} \\
\text { diameter for } \\
\text { plaque type }\end{array}$ & $\begin{array}{c}13 \times 125 \times 13 \mathrm{~mm} \\
\text { diameter }\end{array}$ & $\begin{array}{c}\text { long of } 250 \mathrm{~mm} \text { rod } \\
\text { specimen (thickness } 4 \\
\mathrm{~mm}\end{array}$ \\
\hline & & & $13 \times 125 \times 5 \mathrm{~mm}$ & & rod narrow section \\
\hline & & & diameter for bar & & width \\
\hline & & & type & & $6 \mathrm{~mm})$ \\
\hline & 5 & 10 & $6+6$ & 10 & 3 \\
\hline & 10 & 10 & $6+6$ & 10 & 3 \\
\hline \multirow{4}{*}{$\mathrm{AH}$} & 15 & 10 & $6+6$ & 10 & 3 \\
\hline & 20 & 10 & $6+6$ & 10 & 3 \\
\hline & 25 & 10 & $6+6$ & 10 & 3 \\
\hline & 30 & 10 & $6+6$ & 10 & 3 \\
\hline
\end{tabular}

TGA of composites from room temperature to $800{ }^{\circ} \mathrm{C}$ at a heating rate of $10{ }^{\circ} \mathrm{C} / \mathrm{min}$ was carried out using a SETERAM Thermal Gravimetric Analyzer. Nitrogen was used as a carrier gas with a constant flow rate during analysis. TGA analysis was performed in order to determine the effect of additives on decomposition behavior of composite under heat effect. In TGA analysis, test samples were prepared without matt felt fiber in order to determine the effect of the additives more clearly. Average of 8-10 mg samples were taken from all matrix (including reference) to use in TGA analysis. A total of 600 samples were produced with the aim of applying the flame test on composite samples in accordance with all angles, heights and application positions of flame detailed in ASTM standards. In experimental studies, the optimum amount of resin used in the production of hand lay-up composites was determined as 300 grams after preliminary tests considering the effect of the impregnation of the fibers and the effect of the powder additives on the resin consistency.

In the first step of sample production, resin was weighted (Figure 3(a)). Then, cobalt octoate (as accelerator) was added to the resin as $1 \%$ by weight of resin and mixing procedure was started (Figure $3(\mathrm{~b})$ ). When the resin+cobalt octoate mixture became homogeneous, it was continued to be mixed slowly by adding $1 \%$ methyl ethyl ketone peroxide (as initiator) (Figure 3(c)).
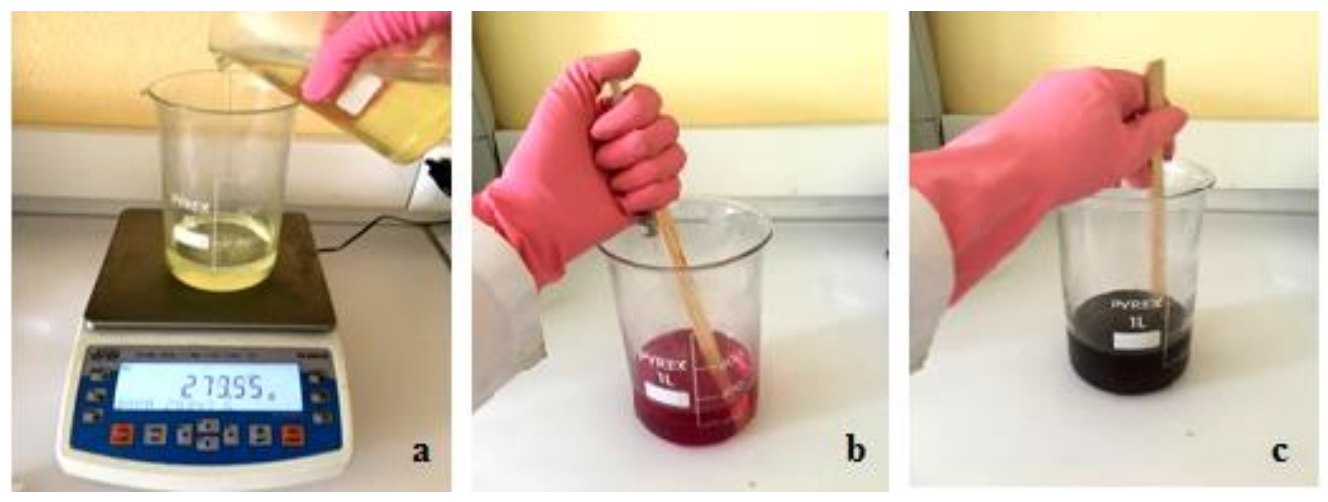

Figure 3. Preparation of resin matrix: (a) Weighting resin; (b) Cobalt octoate addition and mixing; (c) MEK-P addition and mixing

After the addition of accelerator and initiator to the resin, AT, ZB and AH at rates of 5\%, 10\%, 15\%, 20\%, 25\% and 30\% were added to the mixture and mixing process applied by a rod until a homogeneous form is provided. Burning resistance tests on the composites were performed according to ASTM D-635, ASTM D-3801, ASTM-D5048 standards through combustion chamber test setup given in Figure $4((\mathrm{a}),(\mathrm{b}))$.In burning tests, flame heights and flame angles $\left(20^{\circ}\right.$ and $45^{\circ}$ angle with $20 \mathrm{~mm}$ and $125 \mathrm{~mm}$ elevation) were variables 
and also flame exposure (horizontal / vertical) was applied in two positions according to the ASTM standards. Details of combustion tests were given in Figure 5((a),(b),(c)).
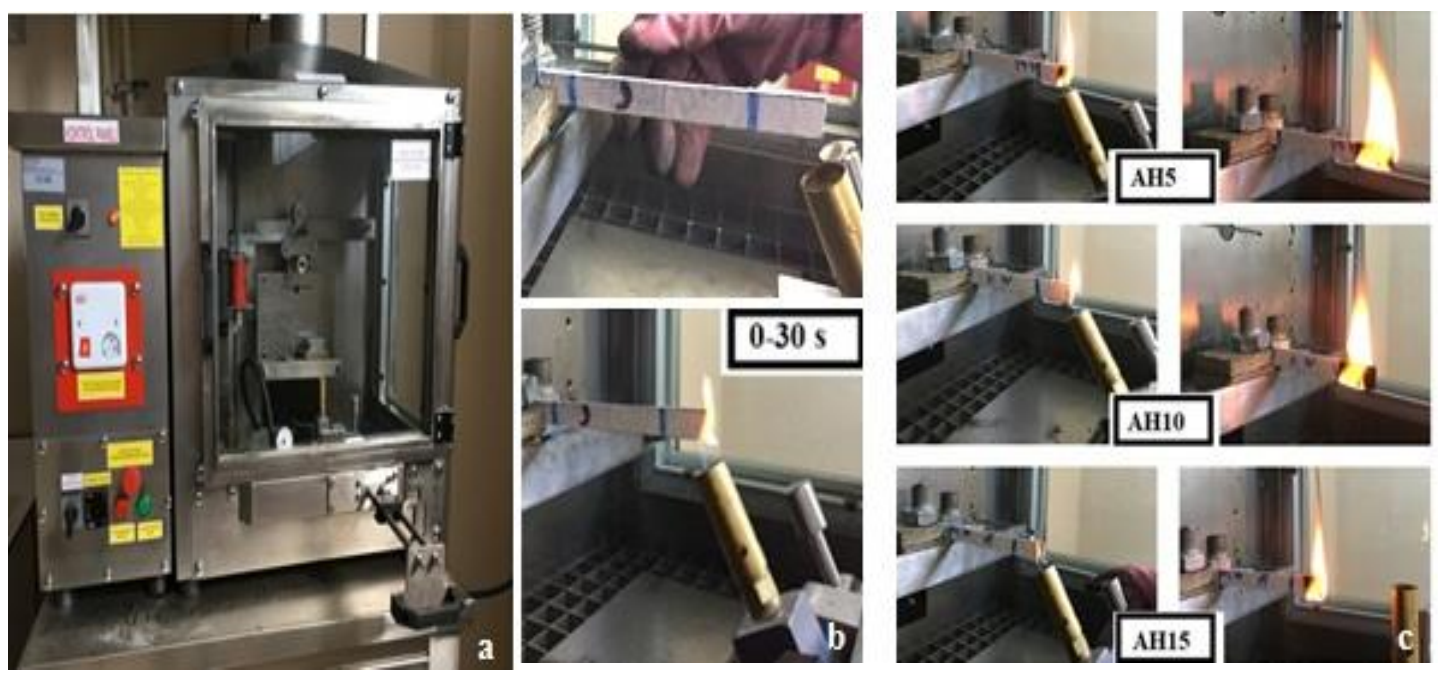

Figure 4. (a) Combustion chamber test; (b) An application of test
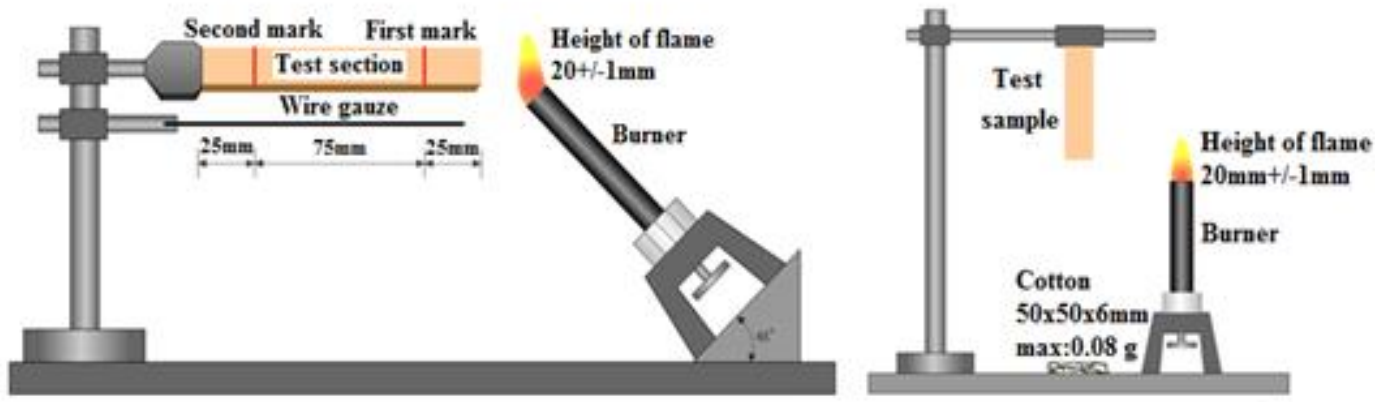

a

b
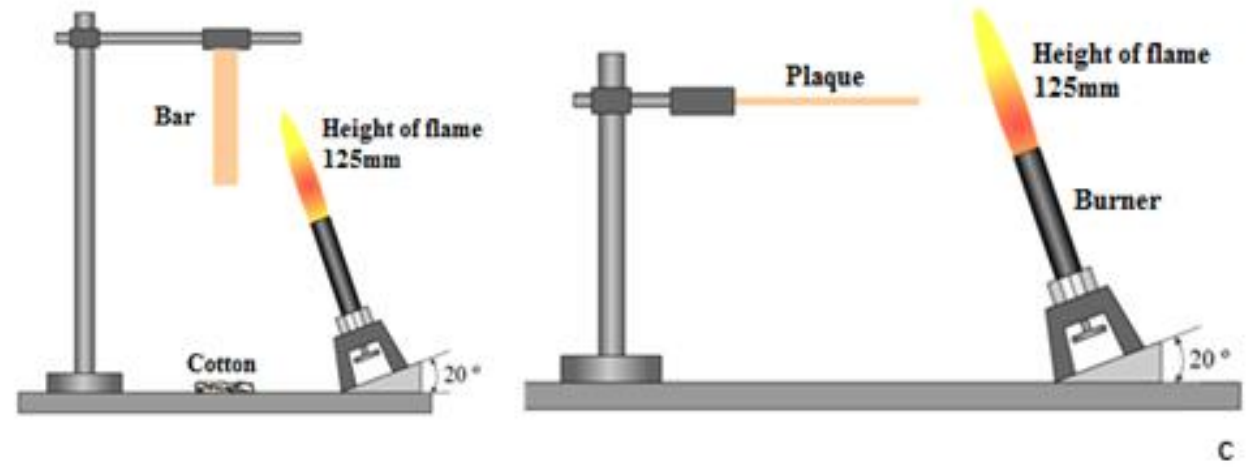

Figure 5. Burning tests application details (a)ASTM D-635 (b)ASTM D-3801 (c)ASTM D-5048

In addition to burning tests, axial tensile strength test was applied on samples to observe the effects of FRs on mechanical performances of composites. In the axial tensile test, notched samples were used. The appearance of the notched samples before and after the experiment is given in Figure 6. In the tensile strength tests, notched samples were used and the loading rate was determined as $5 \mathrm{~mm}$ / min according to ASTM 638-14. 

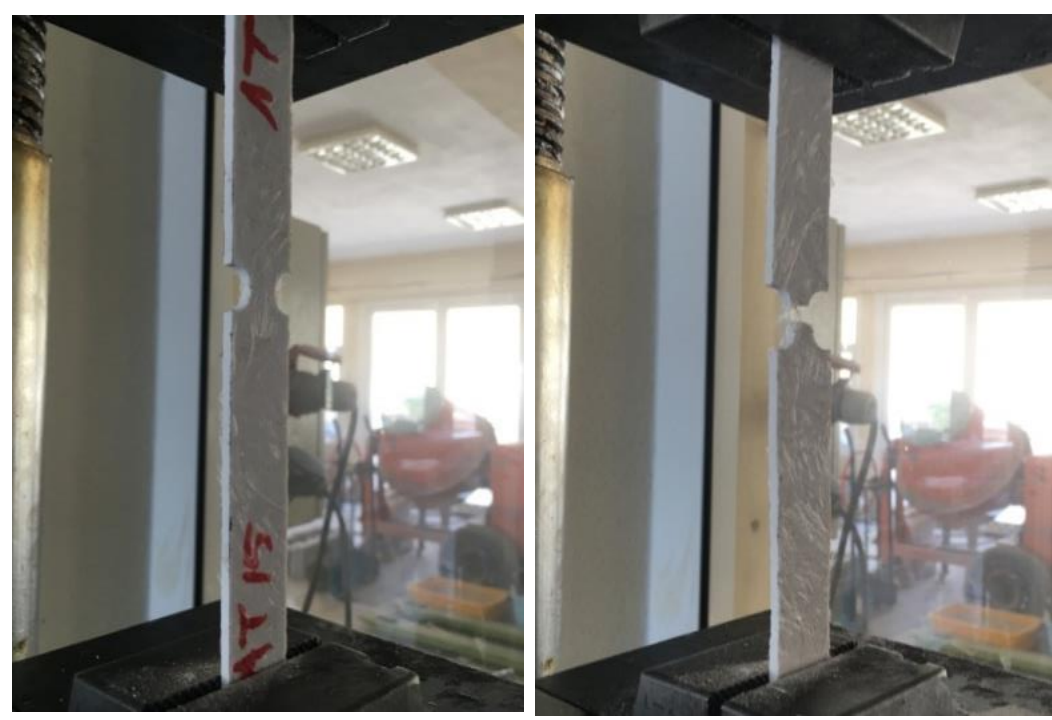

Figure 6. Condition of notched samples before tensile test and after tensile testing

\section{Results and Discussions}

\subsection{Thermogravimetric Analysis (DTA-TGA)}

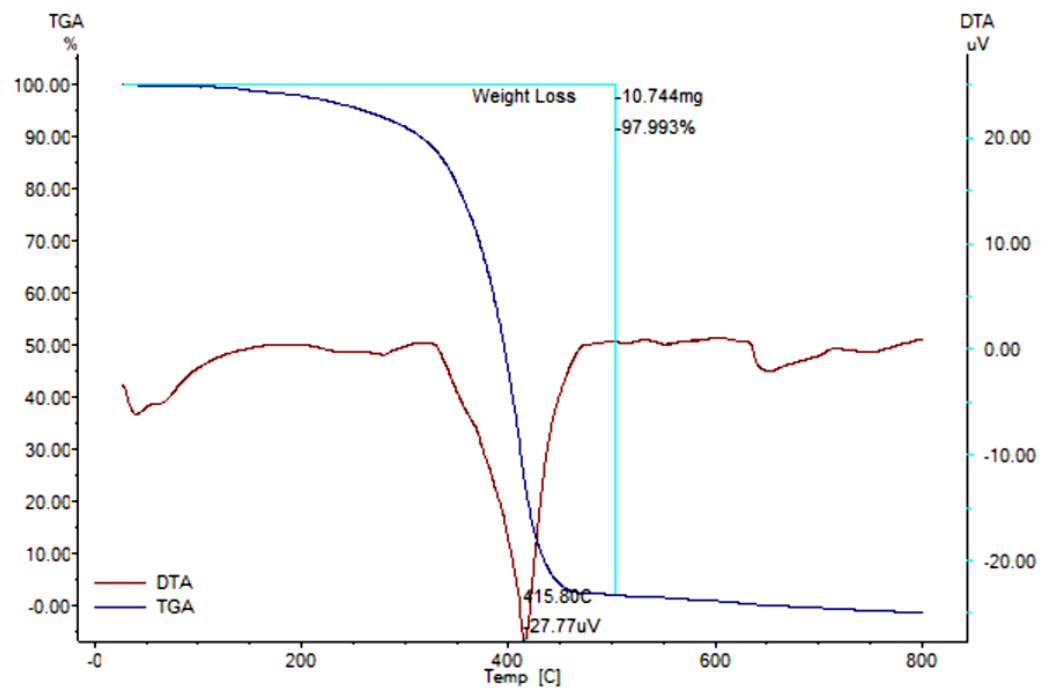

Figure 7. TGA-DTA diagram for reference sample 


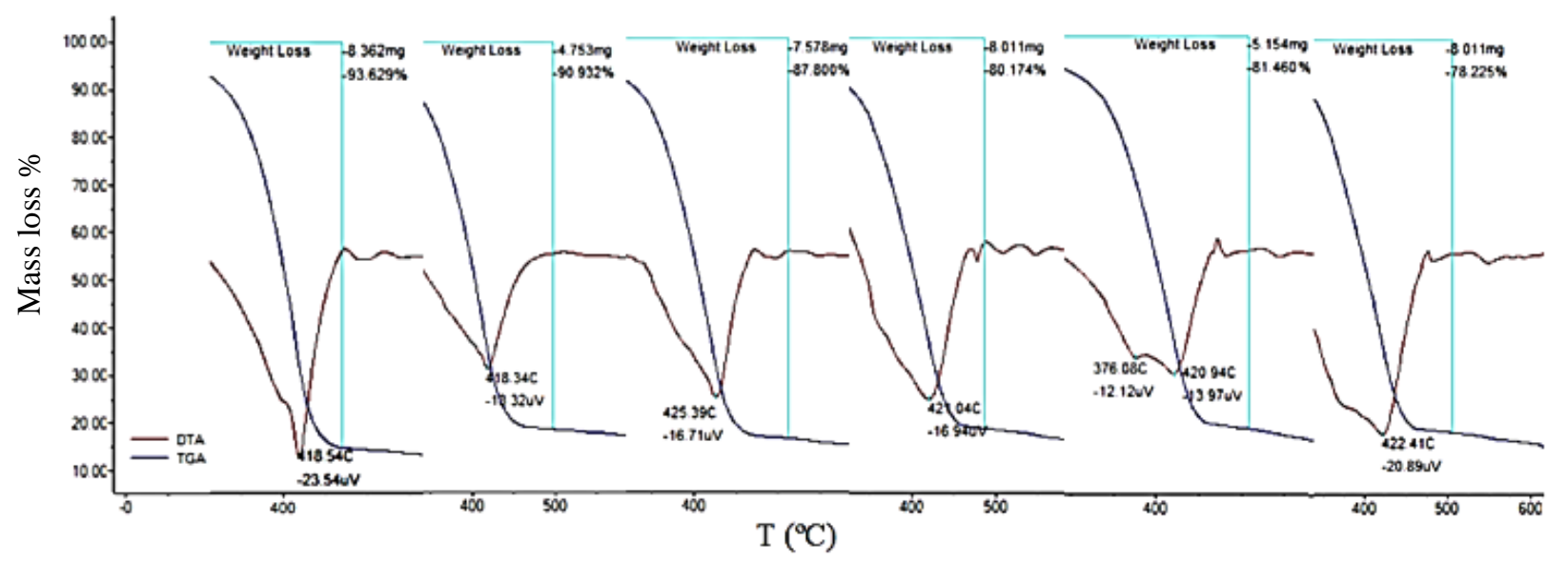

Figure 8. TGA-DTA diagram for composite samples containing AH

TGA-DTA curves of all composites containing FRs were illustrated in Figs. 8-11. AH added composites were analyzed as an example and the others were summarised in Table 5. According to the Fig.8, the endothermic peak values of the $\mathrm{AH}$ added composite samples were determined as $414,45^{\circ} \mathrm{C}, 412,10^{\circ} \mathrm{C}, 386,33^{\circ} \mathrm{C}, 399,38^{\circ} \mathrm{C}, 390,78^{\circ} \mathrm{C}$ and $415,68{ }^{\circ} \mathrm{C}$ for AH5, AH10, AH15, AH20, AH25 and AH30 coded samples, respectively.

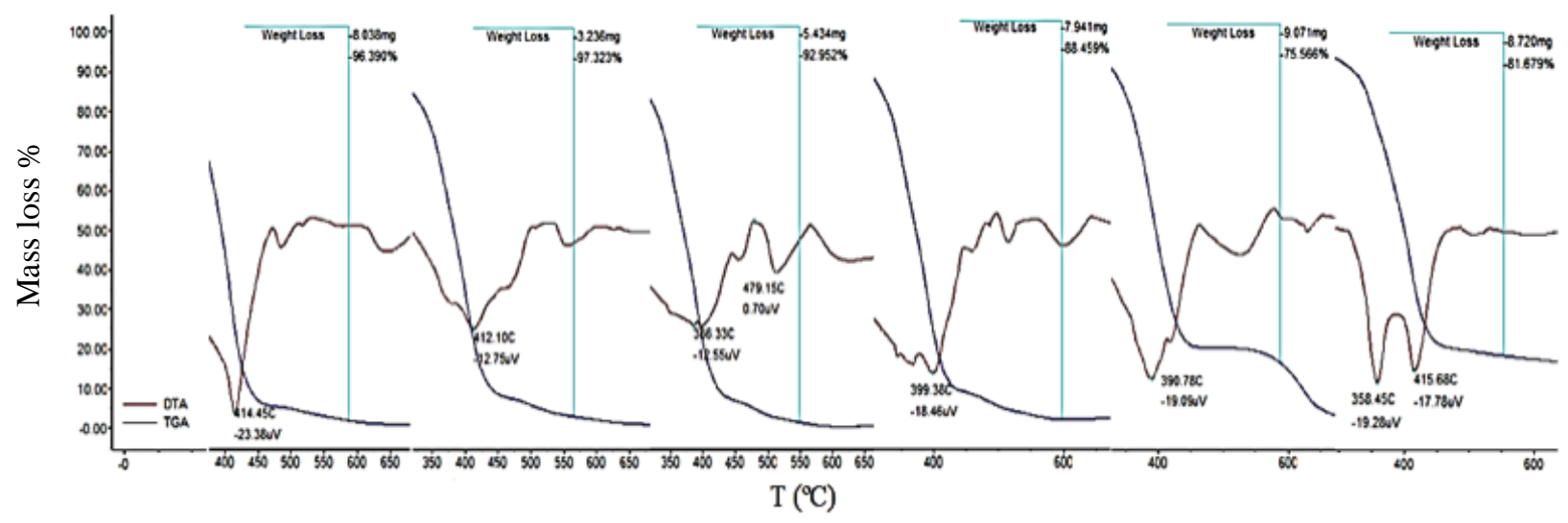

Figure 9. TGA-DTA diagram for composite samples containing AT

The mass losses of composites were found as $96.390 \%$ for AH5 (between 50 and $580{ }^{\circ} \mathrm{C}$ ), $97.323 \%$ for $\mathrm{AH} 10$ (between 25 and 560 ${ }^{\circ} \mathrm{C}$ ), $92.952 \%$ for $\mathrm{AH} 15$ (between 25 and $550{ }^{\circ} \mathrm{C}$ ), $88.459 \%$ for AH20 (between 30 and $600{ }^{\circ} \mathrm{C}$ ), $75.566 \%$ for AH25 (between 20 and $590{ }^{\circ} \mathrm{C}$ ) and $81.679 \%$ for $\mathrm{AH} 30$ (between 20 and $550{ }^{\circ} \mathrm{C}$ ). The endothermic peak values and mass losses of composites containing other FRs were detailed in Table 5.

Table 5. Mass loss value the composites according to TGA analysis

\begin{tabular}{lllll}
\hline $\begin{array}{l}\text { Sample } \\
\text { code }\end{array}$ & $\begin{array}{l}\text { Mass loss } \\
(\mathbf{w t .} \%)\end{array}$ & $\begin{array}{l}\text { I-F temperature of } \\
\text { mass losses } \\
\left({ }^{\mathbf{} C} \mathbf{C}\right)\end{array}$ & $\begin{array}{l}\text { Temperature of } \\
\text { maximum mass } \\
\text { loss } \\
\left({ }^{\circ} \mathbf{C}\right)\end{array}$ \\
\hline REF & 97,99 & 35 & 550 & 415,80 \\
AH5 & 96,39 & 50 & 580 & 414,45 \\
AH10 & 97,32 & 25 & 560 & 412,10 \\
AH15 & 92,95 & 25 & 550 & 386,33 \\
AH20 & 88,45 & 30 & 600 & 399,38 \\
AH25 & 75,56 & 20 & 590 & 390,78 \\
AH30 & 81,67 & 20 & 550 & 415,68 \\
ZB5 & 93,08 & 20 & 500 & 409,00 \\
ZB10 & 91,37 & 25 & 500 & 408,40 \\
ZB15 & 85,66 & 20 & 490 & 408,40 \\
ZB20 & 84,84 & 75 & 515 & 410,54 \\
ZB25 & 80,31 & 26 & 600 & 406,54 \\
\hline
\end{tabular}


Table 5 (devam). Mass loss value the composites according to TGA analysis

\begin{tabular}{lllll}
\hline $\begin{array}{l}\text { Sample } \\
\text { code }\end{array}$ & $\begin{array}{l}\text { Mass loss } \\
(\mathbf{w t .} \%)\end{array}$ & $\begin{array}{l}\text { I-F temperature of } \\
\text { mass losses } \\
\left({ }^{\mathbf{O}} \mathbf{C}\right)\end{array}$ & $\begin{array}{l}\text { Temperature of } \\
\text { maximum mass } \\
\text { loss } \\
\left({ }^{\circ} \mathbf{C}\right)\end{array}$ \\
\hline ZB30 & 81,67 & 150 & 550 & 402,51 \\
AT5 & 96,39 & 20 & 640 & 388,80 \\
AT10 & 92,53 & 50 & 600 & 394,58 \\
AT 15 & 90,16 & 75 & 600 & 395,58 \\
AT 20 & 74,92 & 25 & 570 & 390,78 \\
AT 25 & 74,82 & 20 & 525 & 392,42 \\
AT 30 & 96,28 & 25 & 600 & 402,93 \\
I :Initial; F: Flammability & & & \\
\hline
\end{tabular}

\subsection{Burning Behaviors of Composites}

3.2.1. Burning test results of $125 \mathrm{~mm}$ flame height application (ASTM D-5048)

In the observations made after the burning test, color change occurred very clearly on the reference sample. In some samples containing additives, color changes were observed, although not as much as the reference sample. The images of all plates after ASTM D-5048 burning test were shown in Figure 11.

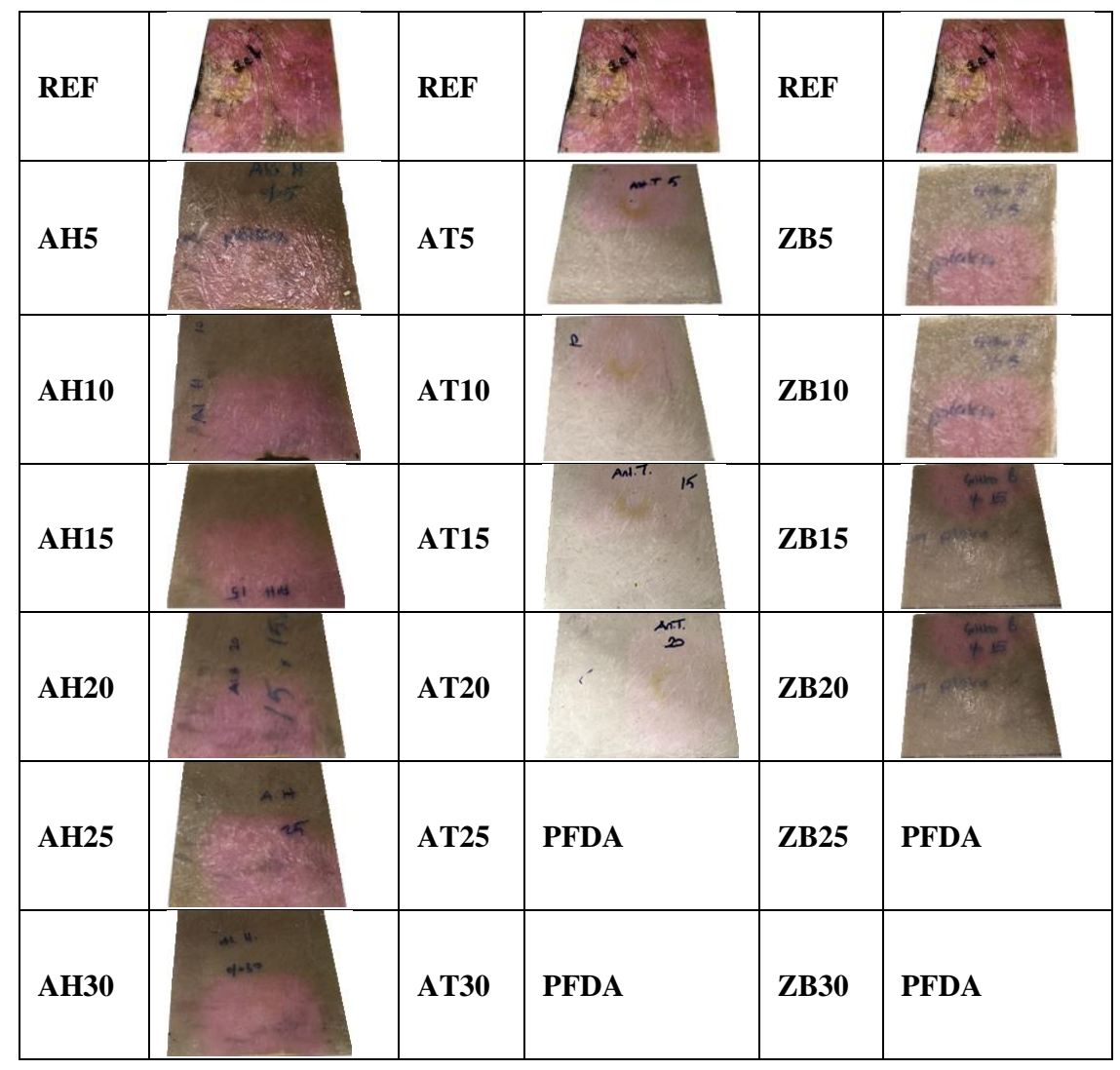

Figure 11. Images of All Plates After Astm D-5048 Burning Test

As seen in the figure, there was no puncture occurred on all plates and all samples showed a non-flammable material behavior according to ASTM D-5048 burning test. According to observational analysis when different additive types were compared among each other, all samples containing AH showed similar results and the increase of the additive content did not affect the color change on the surface under burning effect. It was observed that the color changed area decreased with the increase in the percentage of AT addition under the effect of flame. The behavior similar to the samples containing AT addition was also observed in the samples containing the ZB addition.

\subsubsection{Vertical burning test (ASTM D3801)}

Vertical burning test was applied to the samples according to ASTM D3801 standard. Figure 12 shows the images of composite samples produced at each percentage rate $(5 \%, 10 \%, 15 \%, 20 \%, 25 \%$ and $30 \%)$ after the vertical burning test. 


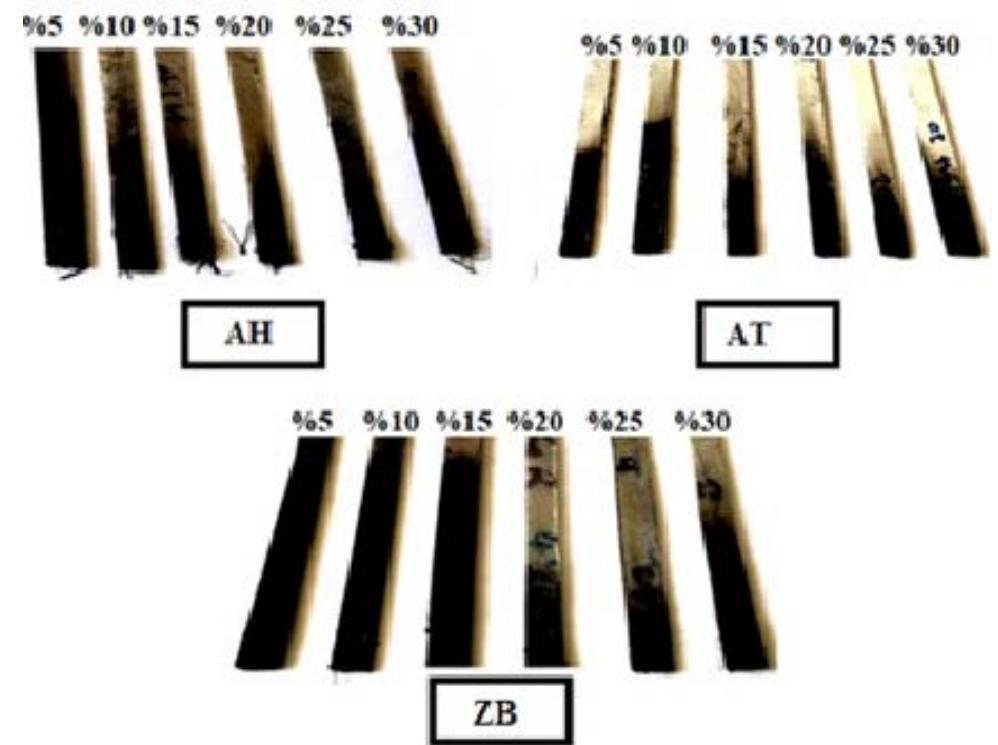

Figure 12. Post-burning images of composite samples after vertical burning test

In the vertical burning tests applied to the reference samples, the combustion behavior started in the first ten seconds and then continued increasingly. In the experiment, the whole body of non-additive reference sample was burnt. The combustion classes determined in ASTM D-3801 for vertical burning test were given in Table 6.

Table 6. Classifications of materials according to the ASTM D 3801 standard

\begin{tabular}{llll}
\hline Criteria conditions & V-0 & V-1 & V-2 \\
\hline After-flame time for each individual specimen ( $\mathrm{t}_{1}$ or $\left.\mathrm{t}_{2}\right)$ & $\leq 10 \mathrm{~s}$ & $\leq 30 \mathrm{~s}$ & $\leq 30 \mathrm{~s}$ \\
$\begin{array}{l}\text { Total after-flame time for each specimen } \\
\text { set }\left(\mathrm{t}_{1}+\mathrm{t}_{2} \text { for the five specimens) }\right.\end{array}$ & $\leq 50 \mathrm{~s}$ & $\leq 250 \mathrm{~s}$ & $\leq 250 \mathrm{~s}$ \\
$\begin{array}{l}\text { After-flame plus afterglow time for each individual } \\
\text { specimen after the secondflame application }\left(\mathrm{t}_{2}+\mathrm{t}_{3}\right)\end{array}$ & $\leq 30 \mathrm{~s}$ & $\leq 60 \mathrm{~s}$ & $\leq 60 \mathrm{~s}$ \\
$\begin{array}{l}\text { After-flame of any specimen up to the holding clamp } \\
\text { Cotton indicator ignited by flaming particles or drops }\end{array}$ & NO & NO & NO \\
\hline
\end{tabular}

According to the findings, the fire resistance classes of all samples were given in Table 7 . When Table 7 is examined, it is seen that only AT30 and AH30 samples correspond to V1 (ASTM D-3801 ratings are classified as V-0, V-1, and V-2, ordered by increasing flammability) as non-combustible material classes according to ASTM D-3801.

Table 7. Evaluation of the post-burning states of samples according to ASTM D-3801 standard

\begin{tabular}{|c|c|c|c|c|c|c|c|c|c|c|c|c|c|}
\hline \multirow{2}{*}{$\begin{array}{l}\text { Sample } \\
\text { code }\end{array}$} & \multicolumn{2}{|c|}{$\mathrm{CD}, \mathrm{s}$} & \multicolumn{2}{|c|}{ TCD, $s$} & \multicolumn{2}{|c|}{ CDAFFA, $s$} & \multicolumn{2}{|c|}{$\mathbf{C P}$} & \multicolumn{2}{|c|}{ CI } & \multicolumn{3}{|c|}{ Incombustibility class } \\
\hline & $\leq 10$ & $\leq \mathbf{3 0}$ & $\leq \mathbf{5 0}$ & $\leq \mathbf{2 5 0}$ & $\leq \mathbf{3 0}$ & $\leq 60$ & YES & NO & YES & NO & V0 & V1 & V2 \\
\hline REF & CMS & CMS & CMS & CMS & CMS & CMS & $\checkmark$ & - & CMS & $\checkmark$ & NR & NR & NR \\
\hline AH5 & CMS & CMS & CMS & CMS & CMS & CMS & CMS & $\checkmark$ & CMS & $\checkmark$ & NR & NR & NR \\
\hline AH10 & CMS & CMS & CMS & CMS & CMS & CMS & CMS & $\checkmark$ & CMS & $\checkmark$ & NR & NR & NR \\
\hline AH15 & CMS & CMS & CMS & CMS & CMS & CMS & CMS & $\checkmark$ & CMS & $\checkmark$ & NR & NR & NR \\
\hline AH20 & CMS & CMS & CMS & CMS & CMS & CMS & CMS & $\checkmark$ & CMS & $\checkmark$ & NR & NR & NR \\
\hline AH25 & CMS & CMS & CMS & CMS & CMS & CMS & CMS & $\checkmark$ & CMS & $\checkmark$ & NR & NR & NR \\
\hline AH30 & CMS & $\checkmark$ & CMS & $\checkmark$ & CMS & $\checkmark$ & CMS & $\checkmark$ & CMS & $\checkmark$ & NR & $\checkmark$ & NR \\
\hline
\end{tabular}


Table 7 (devam). Evaluation of the post-burning states of samples according to ASTM D-3801 standard

\begin{tabular}{lcccccccccccccc}
\hline $\begin{array}{l}\text { Sample } \\
\text { code }\end{array}$ & \multirow{2}{*}{ CD, $\mathbf{s}$} & \multicolumn{2}{c}{ TCD, $\mathbf{s}$} & \multicolumn{2}{c}{ CDAFFA, $\mathbf{s}$} & \multicolumn{2}{c}{ CP } & & CI & \multicolumn{3}{c}{ Incombustibility class } \\
\hline & & & & & & & & & & & & \\
\hline ZB5 & CMS & CMS & CMS & CMS & CMS & CMS & CMS & CMS & CMS & $\checkmark$ & NR & NR & NR \\
ZB10 & CMS & CMS & CMS & CMS & CMS & CMS & CMS & CMS & CMS & $\checkmark$ & NR & NR & NR \\
ZB15 & CMS & CMS & CMS & CMS & CMS & CMS & CMS & CMS & CMS & $\checkmark$ & NR & NR & NR \\
ZB20 & CMS & CMS & CMS & CMS & CMS & CMS & CMS & CMS & CMS & $\checkmark$ & NR & NR & NR \\
ZB25 & CMS & CMS & CMS & $\checkmark$ & CMS & CMS & CMS & CMS & CMS & $\checkmark$ & NR & NR & NR \\
ZB30 & CMS & CMS & CMS & $\checkmark$ & CMS & CMS & CMS & CMS & CMS & $\checkmark$ & NR & NR & NR \\
\hline
\end{tabular}

CMS: Couldn't match standart; CD:Combustion duration; TCD: Total combustion duration; CDAFFA: Combustion duration after the first flame application; CP: Combustion progress; CI: Cotton ignited by flaming particles NR: No Rated

\subsubsection{Horizontal burning test (ASTM D635-14)}

Horizontal burning test was applied to the samples according to ASTM D635-14 standard. In the reference sample, the flame reached the first $25 \mathrm{~mm}$ boundary line in less than 30 seconds and also the reference samples were completely burned rapidly in this test like other combustion tests. The images of all samples after the horizontal burning test were given in Figure 13.

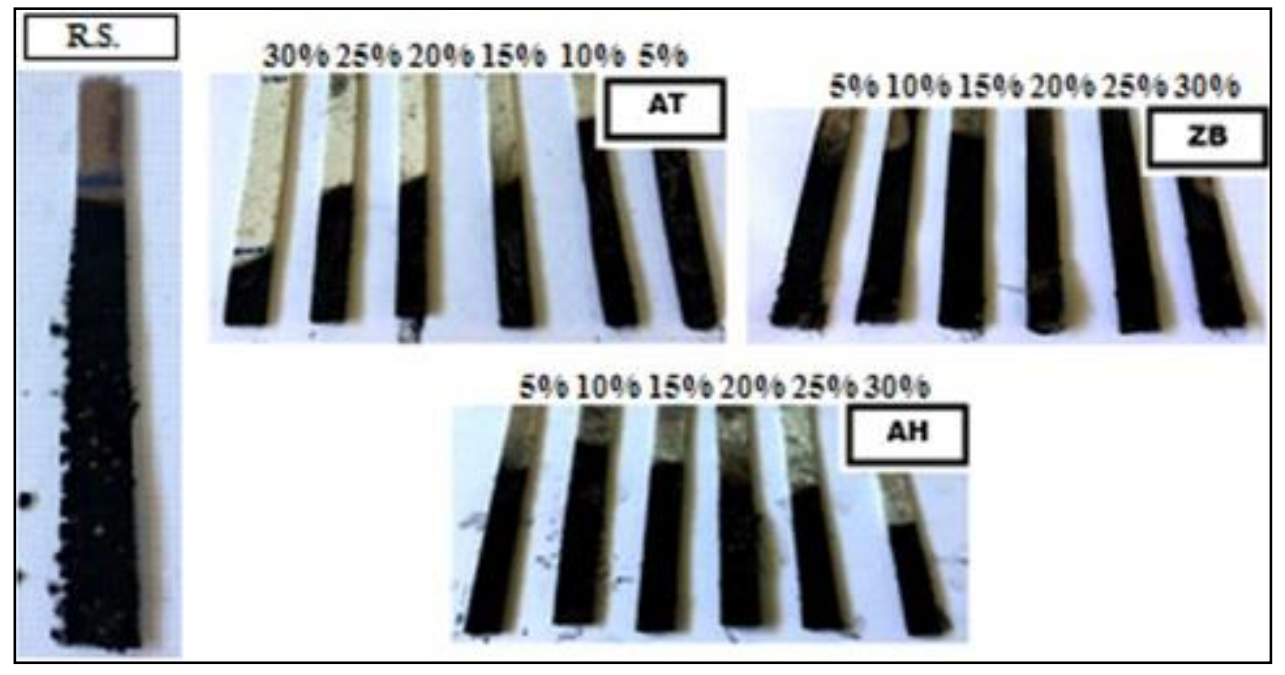

Figure 13. The images of all samples after the horizontal burning test

In the test, the reference sample was completely burned out in a short time shortly after the flame application for 30 seconds. It was concluded that the reference sample has a high burning rate according to the ASTM D-635 classification and exceeds the upper limit of $40 \mathrm{~mm} / \mathrm{min}$ given in standard. According to this result, it can be said that the reference sample cannot be defined in the class of HB-Slow Burning Material according to ASTM D-635 - Horizontal Combustion Test classes. In all samples containing AT, AH and ZB with different ratios, the burning rate slowed down after the burning zone of the sample exceeded $25 \mathrm{~mm}$, which is the reference region. Subsequently, all materials containing AT, AH and ZB with different ratios burned with slow Burning Rate (less than 40 $\mathrm{mm} / \mathrm{min}$ ) up to $75 \mathrm{~mm}$ distance.

According to these behaviors of materials, all materials can be classified as HB-Slow Burning Material according to ASTM D-635. The classifications of all samples according to ASTM D-635 were given in Table 8. 
Table 8. Results of horizontal burning test ASTM D-635 HB for composites and reference sample

\begin{tabular}{ccc}
\hline $\begin{array}{c}\text { Sample } \\
\text { code }\end{array}$ & $\begin{array}{c}\text { BR } \mathbf{~ m m} / \mathbf{m i n} \\
\leq \mathbf{4 0} \mathbf{~ m m} / \mathbf{d k}\end{array}$ & Classification \\
\hline REF & - & HC \\
AH5 & $\checkmark$ & HB \\
AH10 & $\checkmark$ & HB \\
AH15 & $\checkmark$ & HB \\
AH20 & $\checkmark$ & HB \\
AH25 & $\checkmark$ & HB \\
AH30 & $\checkmark$ & HB \\
AT5 & $\checkmark$ & HB \\
AT10 & $\checkmark$ & HB \\
AT15 & $\checkmark$ & HB \\
AT20 & $\checkmark$ & HB \\
AT25 & $\checkmark$ & HB \\
AT30 & $\checkmark$ & HB \\
ZB5 & $\checkmark$ & HB \\
ZB10 & $\checkmark$ & HB \\
ZB15 & $\checkmark$ & HB \\
ZB20 & $\checkmark$ & HB \\
ZB25 & $\checkmark$ & HB \\
ZB30 & $\checkmark$ & \\
\hline HB Burning Rate less than $40 \mathrm{~mm} / \mathrm{min}$
\end{tabular}

3.2.4. Axial tensile test (ASTM D638-14)

The average tensile strength results of all samples were presented in Table 9. According to the results in Table 9, the maximum tensile strengths were found as 138,32 MPa, 181,63 MPa, 146,21 MPa, $132 \mathrm{MPa}$ in AH 20, AT10 and ZB15 coded samples according to the additive types. The minimum tensile strengths were found as 121,89 MPa,127,74 MPa, 105,00 MPa and 98,60 MPa for AH15, AT20 and ZB25 respectively.

Table 9. Tensile test result of composites and reference sample

\begin{tabular}{cc}
\hline $\begin{array}{c}\text { Sample } \\
\text { code }\end{array}$ & $\begin{array}{c}\text { Avarage } \\
\text { tensile strength (MPa) }\end{array}$ \\
\hline REF & 152.33 \\
AH5 & 131.62 \\
AH10 & 134.44 \\
AH15 & 121.89 \\
AH20 & 138.32 \\
AH25 & 135.26 \\
AH30 & 128.97 \\
AT5 & 142.49 \\
AT10 & 181.63 \\
AT15 & 146.54 \\
AT20 & 127.74 \\
AT25 & 140.83 \\
AT30 & 142.54 \\
ZB5 & 124.49 \\
ZB10 & 121.28 \\
ZB15 & 146.21 \\
ZB20 & 105.27 \\
ZB25 & 105.00 \\
ZB30 & 109.64
\end{tabular}

Note: Three specimens were tested and their average

values were noted.

The relative comparison of tensile strength results were given in Fig. 14 (a-d). It is clearly seen in Figure 14 (a-d) that only AT5 coded samples' tensile strength was found higher than reference sample. The most significant decreases in tensile strengths were observed in samples containing ZB in comparison to the reference sample. 

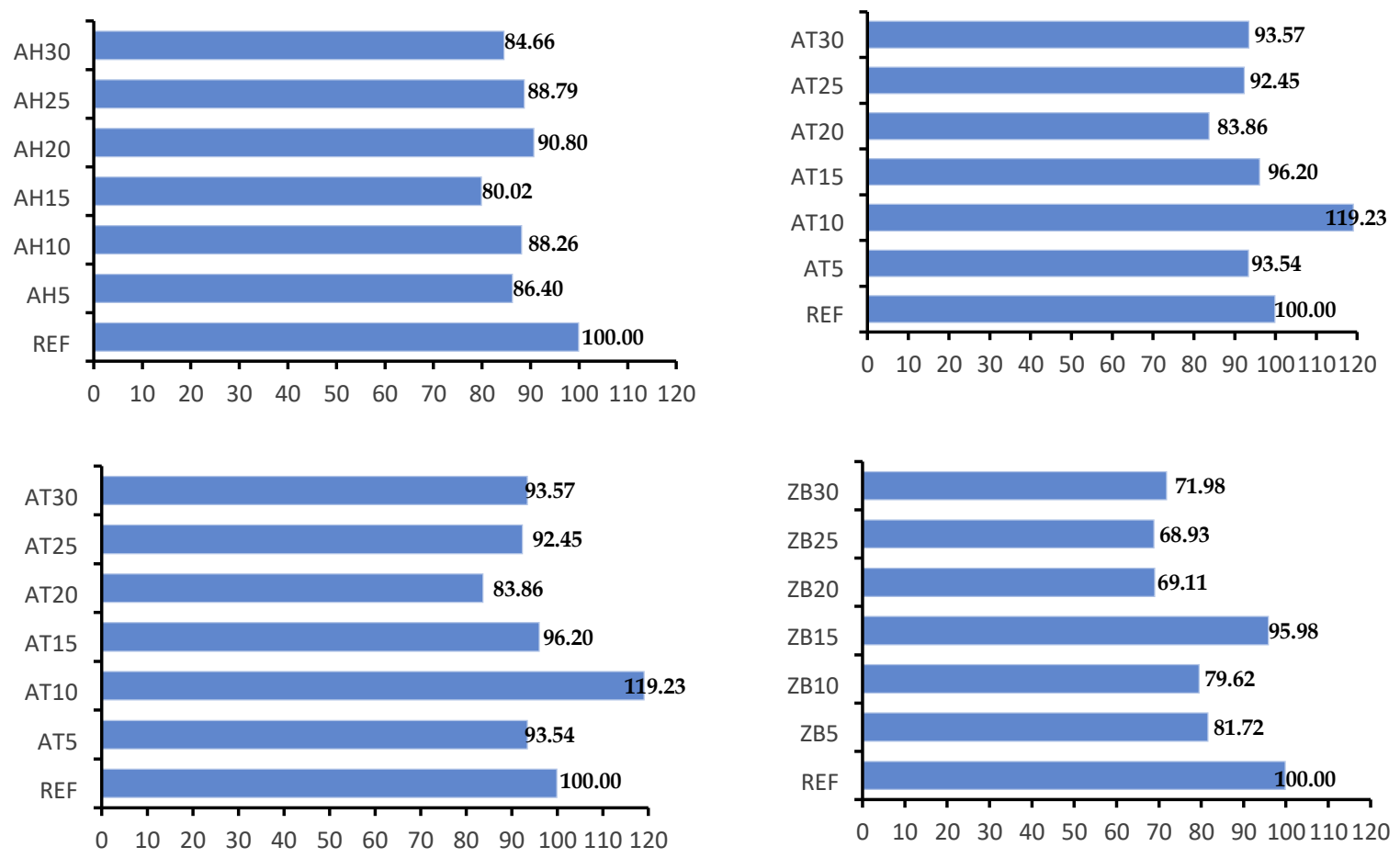

Figure 14. The relative comparison of tensile strength

When the experimental findings and relative comparison graphs are analyzed, it can be concluded that FR addition decreases the tensile strength. Furthermore, it is difficult to establish a meaningful relationship between the amount and type of additive and tensile strength. The highest tensile strength among all samples was found in the mixture coded as AT10.

\section{Conclusions}

\section{Non-Flammability behavior of the composites}

There was no puncture occurred on all plates (reference plate and plates produced by using FRs) thus all samples can be evaluated as non-flammable material according to the ASTM D-5048. It has been observed that the increase in the percentage of AT, ZB and AH addition caused a decrease in the area effected by combustion.

Composites containing 30\% AT and 30\% AH correspond to V1 which means the non-combustible material classes according to ASTM D-3801. Zhu et al., 2019 had already tried to explain non-combustible behavior of AH through the released water of crystallization. According to them the hydroxides in $\mathrm{Al}(\mathrm{OH})_{3}$ may release water of crystallization when they are heated, absorbing part of the heat produced during the burning process, thus reducing the surface temperature of the materials and decreasing their rate of degradation. The results found in this research confirms to their research results.

Whereas the reference sample could not be classified as HB Slow Burning Material according to ASTM D-635, all samples containing AT, AH and ZB in different ratios should be classified as HB.

\section{Mechanical properties of the composites}

When the tensile strength results of the composite materials are examined; 10\% AT added composite material showed higher tensile strength than the reference sample. Except 10\% AT added composite, the tensile strengths of all composite samples containing flame retardant additives decreased. Although it has been observed that the use of additives decreases the tensile strength of composites, it is difficult to establish a meaningful relationship between the amount/type of additive and tensile strength.

\section{Acknowledgment}

This study was supported by Düzce University Scientific Research Projects Coordination Unit (Project No: 2017-0705527).

\section{References}

Bar, M., Alagirusamy, R., Das, A. (2015). Flame retardant polymer composites. Fibers and Polymers. 16, 705-717. 
Bulut, Y., Erdoğan Ü. H. (2011). Usability of cellulose based natural fibers as reinforcement materials in composite manufacturing. Journal of Textiles and Engineer. 82, 26-35.

Camino, G., Costa, L., Cortemiglia, L. (1991). Polymer degradation and stability. Journals \& Books. 33(2), 131-154. doi:10.1016/0141-3910(91)90014-I

Carpentier, F., Bourbigot, S., Le Bras., M. (2000). Charring of fire retarded ethylene vinyl acetate copolymer magnesium hydroxide/zinc borate formulations. Polymer Degradation and Stability. 69 (1), 83-92. doi:10.1016/S0141-3910(00)00044-6

Cullis, C.F., Hirschler., M.M. (1981). The combustion of organic polymers. Clarendon Press, Oxford.

Dittenber, B.D., Gangaroa, V.S.H. (2006). Composites part a: Applied science and manufacturing. Journals \& Books 43 (8), $1419-$ 1429. doi:10.1016/j.compositesa.2011.11.019

Guan, F.L., Gui, C.X., Zhang, H.B. (2016). Enhanced thermal conductivity and satisfactory flame retardancy of epoxy/alumina composites by combination with graphene nanoplatelets and magnesium hydroxide. Compos Part B: Eng. 98 (1),134-140. doi:10.1016/j.compositesb.2016.04.062

Hong, C.H., Lee, YB. (2005). Tensile properties and stress whiting of polypropylene/polyolefin elastomer/magnesium hydroxide flame retardant composites for cable insulating application. Journal of Applied Polymer Science 97 (6), 2311-2318. doi:10.1002/app.21776

Hornsby, P.R. (1994). The application of magnesium hydroxide as fire retardant and smoke-suppressing additive for polymers. Fire and Materials. 18, 269-276. doi:10.1002/fam.810180502

Kaya, A.İ. (2016). Composite Materials and Their Properties.Putech \& Composites Magazine.

Maira, B., Chammingkwan, P., Terano, M. (2015). New reactor granule technology for highly filled nanocomposites: effective flame retardation of polypropylene/magnesium hydroxide nanocomposites. Macromolecular Materials and Engineering. 300 (7),679-683. doi:10.1002/mame.201500012

Manfredi, B.L., Rodriguez, S. E., Wladyka-Przybylak, M., Vázquez, A. (2006). Thermal degradation and fire resistance of unsaturated polyester, modified acrylic resins and their composites with natural fibres. Polymer Degradation and Stability. 91 (2). 255-261. do:10.1016/j.polymdegradstab.2005.05.003

Raghavendra, T., Kavan, P. (2018). A novel study on thermal stability of camphor soot reinforced coir fibers. Fibers and Polymers. 19, 1567-1575. doi:10.1007/s12221-018-8033-2

Saçak, M. (2005). Polymer Technology, 1th edition. Ankara

Sain, M., Park, S.H., Suhara, F. (2004). Flame retardant and mechanical properties of natural fibre-PP composites containing Magnesium hydroxide. Polym Degrad Stab. 83 (2),363-367. doi:10.1016/S0141-3910(03)00280-5

Sangcheol, K. (2003). Flame retardancy and smoke suppression of magnesium hydroxide filled polyethylene. Journal of Polymer Science Part B Polymer Physics. 41 (9), 936-944. doi:10.1002/polb.10453

Sorathia, U., Rollhauser, C, M., Hughes, W.A. (1992). Improved fire safety of composites for naval applications. Fire and Materials. 16, 119-125. doi:10.1002/fam.810160303

Tasdemir, M., Caneba, G.T., Tiwari, R. (2011). Characterization of PP/Mg $(\mathrm{OH})_{2}$ and PP/nanoclay composites with supercritical $\mathrm{CO}_{2}$ $\left(\mathrm{scCO}_{2}\right)$. Polymer-Plastics Technology and Engineering. 50 (10), 1064-1070. doi:10.1080/03602559.2011.557919

Titelman, G.I., Gonen, Y. (2002). Discolouration of polypropylene-based compounds containing magnesium hydroxide. Polymer Degradation and Stability. 77 (2), 345-352

Valery, V., Evgeny, I. (2001). Mechanics and Analysis of Composite Materials.

Zhu, Z.M., Shang, K., Wang, L.X., Wang, J.S. (2019). Synthesis of an effective bio-based flame-retardant curing agent and its application in epoxy resin: Curing behavior, thermal stability and flame retardancy. Polymer Degradation and Stability. 167. 179-178. doi:10.1016/j.polymdegradstab.2019.07.005 